\title{
Studies of properties of polypropylene/halloysite composites
}

\author{
Agnieszka Szczygielska ${ }^{1}$, Jacek Kijeński ${ }^{2}$ \\ ${ }^{1}$ Industrial Chemistry Research Institute, ul. Rydygiera 8, 01-793 Warszawa, Poland, e-mail: Agnieszka.Szczygielska@ichp.pl \\ ${ }^{2}$ Warsaw University of Technology, School of Technical and Social Sciences, ul. Łukasiewicza 17, 09-400 Ptock, Poland
}

\begin{abstract}
The results of the studies on the synthesis, mechanical and thermal properties of polypropylene composites with various amount of halloysite filler are presented. Halloysite (HNT) belongs to the silica type characterized by a two-layer 1:1 structure. This work was aimed to develop a method for the modification of halloysite in its prime use as a filler for polypropylene by extrusion. The composites contain 1, 3, 5 and $7 \mathrm{wt} . \%$ of HNT. The degree of crystallinity of the composites decrease with increasing halloysite content. The results confirm the expectations that composites of interesting physicochemical, mechanical and thermal properties can be obtained. The mechanical properties studied show that the filler modification method used leads to the synthesis of polymer composites of improved thermal and mechanical properties.
\end{abstract}

Keywords: polypropylene, composites, powder filler, halloysite, mechanical, thermal properties, morphology of polymeric materials, extrusion, injection.

\section{INTRODUCTION}

Halloysite (HNT) belongs to the silica type characterized by a two-layer structure $1: 1^{1,2}$. The halloysite structure, similarly to kaolin, consists of tetrahedral $\mathrm{SiO}_{4}$ groups and octahedral groups of oxygen ions, common to $\mathrm{SiO}_{4}$ groups and $\mathrm{Al}^{3+}$ hydroxyl ions which form multiple layers. The structure of layers of tetrahedral and octahedral halloysite- hydrogenated aluminosilicate $\mathrm{Al}_{4} \mathrm{Si}_{4} \mathrm{O}_{10}(\mathrm{OH}) \cdot 4 \mathrm{H}_{2} \mathrm{O}$ is illustrated in Fig.1 while the typical layer of nanotube-like structure of dehydrated halloysite is presented in Fig. $2^{1,3-4}$.

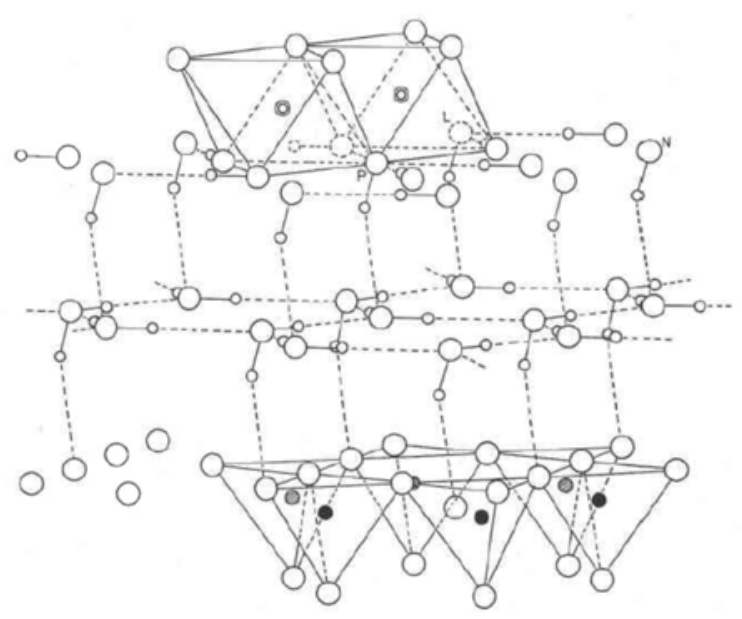

Figure 1. Hydrohalloysite structure ${ }^{3}$
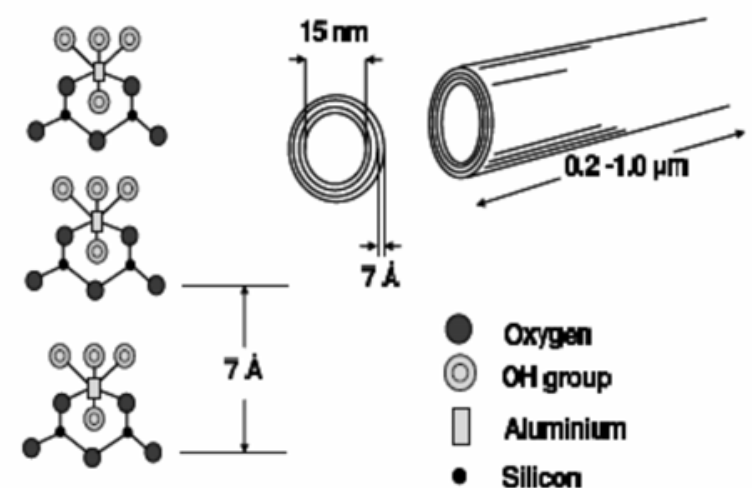

The molecules of water make a monomolecular layer between the layers 1 .

In the hydrogenated form of halloysite, the distance between the surfaces is $10,1 \AA$ while in the dehydrated form it is $7,2 \AA$ as presented in Fig.2. The difference of the distance corresponds with the thickness of the monomolecular layer of water molecules ${ }^{\mathbf{5}, \mathbf{6}}$. Halloysite is a type of mineral clay with a specific structure of layers of nanotubes, and is characterized by high porosity and specific surface, high exchangeability of ions (the ability to absorb heavy metals), easy chemical and mechanical modifications. Halloysite - aluminosilicate from Polish deposits "Dunino" has been used as mineral sorbents, insulating mats, coagulating agents, cosmetics clays, fertilizers and pigments for paints $^{7,8}$. PP production has continually been increasing, which is connected with a low cost of its production, processing possibilities and modification properties through the choice of certain fillers, or mixing with other fillers ${ }^{9,10}$. PP and its composites are widely used in car industry, households and electrotechnics. The research concerning obtaining new PP composites is focussed mainly on the choice of correct fillers, which influence the properties of polymeric materials, which depends on the type, the quantity and form of the filler as well as the interaction between the filler and polymer and the process itself and the conditions in which it takes place. The issues concerning reactive mixing constitute modern and exceptionally prospective direction in processing polymeric materials ${ }^{11,12}$. Only 5 articles on polypropylene with halloysite composites were published up to $2010^{13,14,15,16,17}$.

\section{PURPOSE AND RANGE OF THE WORK}

The purpose of this work was to elaborate an effective method of obtaining polymeric composites of a desired structure and properties in which a modified halloysite was used as the filler and polypropylene was used as a polymer matrix.

Range of work was the modification of HNT, obtaining the composites of PP and HNT by extrusion, forming composites by injection moulding and examining the properties of these composites.

Figure 2. Dehydrated halloysite structure ${ }^{4}$ 


\section{EXPERIMENTAL}

\section{Methods of modification of HNT and ways of obtaining the composites.}

In the research the following components were used: HNT - Poland, PP type HP 500J - Bassel - Orlen, acetone - POCH S.A. Unmodified HNT prior to being used as a filler in PP composites was modified thermally at $450^{\circ} \mathrm{C}$ and mechanically using ultrasonic washers of InterSonic at the transducer frequency of $35 \mathrm{kHz}$ and a power of $300 \mathrm{~W}$. PP composites were obtained by extrusion process using the temperature gradient of different heating zones at a range from $180-205^{\circ} \mathrm{C}$. At this stage a Thermo-Haake twin screw extruder (type PTW 16/25D) was used. The extrusion system included four heating zones and a gas reduction area. The extrusion process was monitored and recorded on the hard disc of the computer.

The following parameters were recorded: temperature in all the areas, temperature and pressure in the die, screw rotation speed and torque. For the composites to be obtained by extrusion process a die of a standard diameter of $3 \mathrm{~mm}$ was used. The chosen composites were subjected to the injection moulding process and later underwent applied tests.

\section{Methods of composite testing}

For the characteristics of the surface and structural properties of the composites a method of electro-microscope scan was used. A scanning electro-microscope JEOL JSM - 6490LV with an Energy Dispers Spectroscopy (EDS) was used. The image was captured with a magnification setting of 5000 to $35000 \mathrm{x}$ and accelerating voltage $15-20 \mathrm{kV}$. The tests of mechanical properties of composites were performed using a universal machine of the type Instron 3366. Determination of tensile and flexural properties was done according to relevant norms PN-EN ISO 527-2 and PN-EN ISO 178. The examination of notched impact strength was done by Charpy's method according to the norm PN-EN ISO 179-1. In examining the thermal properties of the composites the DTA method ${ }^{\mathbf{1 8 , 1 9 , 2 0}}$, was applied using a FP85 DTA/DSC Measuring Cell of the FP900-System and for the determination of the dropping point a measuring cell FP 83 with FP 900 Mettler - Toledo was used.

Table 1. Symbols of examined composite samples

\begin{tabular}{|l|l|}
\hline $\begin{array}{l}\text { Symbols of composite } \\
\text { samples }\end{array}$ & General name for the composite \\
\hline PP_HNT_unmod. & PP composite with unmodified HNT \\
\hline PP_HNT_T450 & $\begin{array}{l}\text { PP and HNT thermally mod ified } \\
\text { composite at } 450^{\circ} \mathrm{C}\end{array}$ \\
\hline PP_HNT_us & $\begin{array}{l}\text { PP and HNT ultrasonic modified } \\
\text { composite }\end{array}$ \\
\hline
\end{tabular}
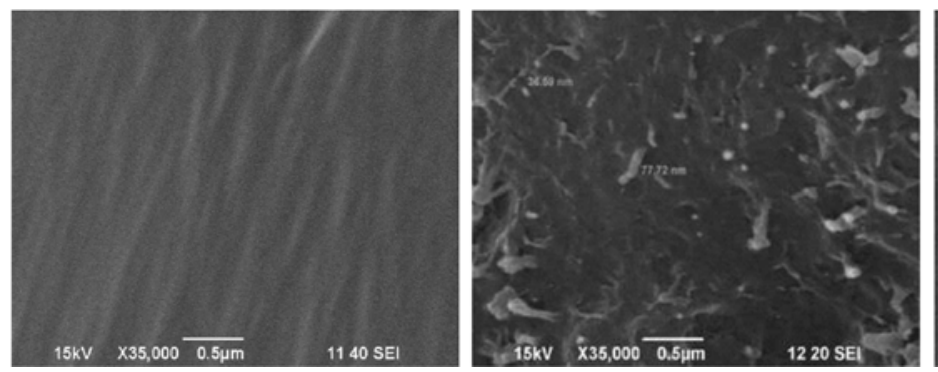

Figure 3. Microphotograph of SEM a) neat PP, b) PP_HNT

\section{RESULTS}

Table 1 presents the symbols used in this paper for the obtained composites.

Examining the morphology of the surface of the composites.

Fig. 3 presents the microphotograph of SEM neat PP and the composites PP_HNT unmod. $_{\text {PP_HNT }}$, PP_HNT 450 containing at $3 \mathrm{wt} . \overline{\%}$ of halloysite.

Fig. 3 shows the effects of HNT loading and surface modification on the dispersion of HNT in PP matrix in comparison with neat PP. It can be seen that most of the HNT are dispersed in PP matrix at nanoscale (Fig. b-d). The modified HNT (Fig. 3c-d) are dispersed more uniformly. However, some aggregates are found in the HNT filled nanocomposites (Fig. 3c), the particles of HNT in the modified system are very uniform. The results of SEM of the obtained composites containing at $3 \mathrm{wt} . \%$ of halloysite show a satisfactory dispersion of HNT particles in the composites. The majority of dispersed HNT particles are characterised by irregular shape and extended surface.

\section{Examining the mechanical properties}

The analysis of the mechanical properties of the composites was performed during static tensile and flexural and notched impact strength by Charpy's method. Fig. 4 presented typical stress - strain curve of PP and chosen composites PP with HNT containing at $3 \mathrm{wt} \%$ of filler. The average value was calculated from the measurements carried out on min. 5 test specimens of composites.

The analysis of the graphs presenting the results of the examination of the mechanical properties of the composites during static tensile test indicates that the examined materials show plasticity limit characterised by the value of tensile strain at yield $\left(\varepsilon_{\mathrm{Y}}\right)$ and tensile stress at yield $\left(\sigma_{\mathrm{Y}}\right)$, tensile strain at tensile strength $\left(\varepsilon_{\mathrm{M}}\right)$, tensile strange at break $\left(\sigma_{\mathrm{B}}\right)$ and maximum tensile stress sustained by the test specimen during a tensile test, tensile strength $(\sigma \mathrm{M})$. Knowing the value of the force acting on the specimen of the known cross-sectional area, all the stress values $(\sigma)$ illustrated in Fig. 5-6 were calculated according to the equation $\sigma=\frac{F}{A}$, where $F$ is the measured force concerned, in newtons, and $\mathrm{A}$ is the initial cross-sectional area of the specimen, expressed in square millimetres. The data presented in Fig. 4-5 show that the increase of the content of modified HNT significantly influences the value of relative elongation and simultaneously increases tension. The influence of the content and HNT modification method on the value of Young's modulus of elasticity and flexural of PP and HNT composites containing 1, 3, 5, $7 \mathrm{wt} . \%$ is presented in Fig. 6-7.
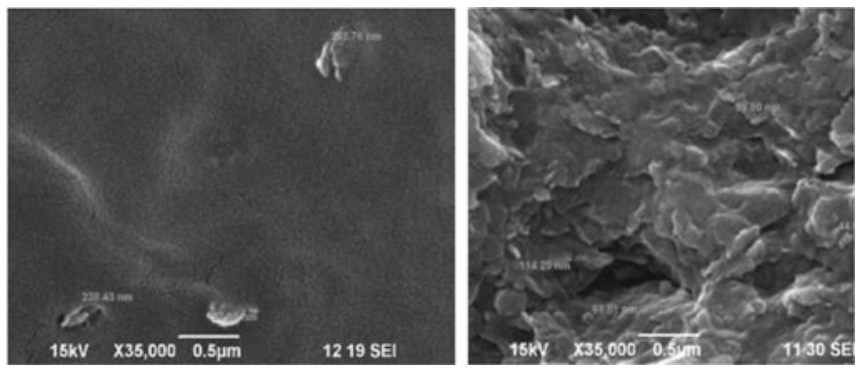

c) PP_HNT $\mathrm{PS}_{-}$, d) $\mathrm{PP}_{-} \mathrm{HNT}_{450}$ 
a)

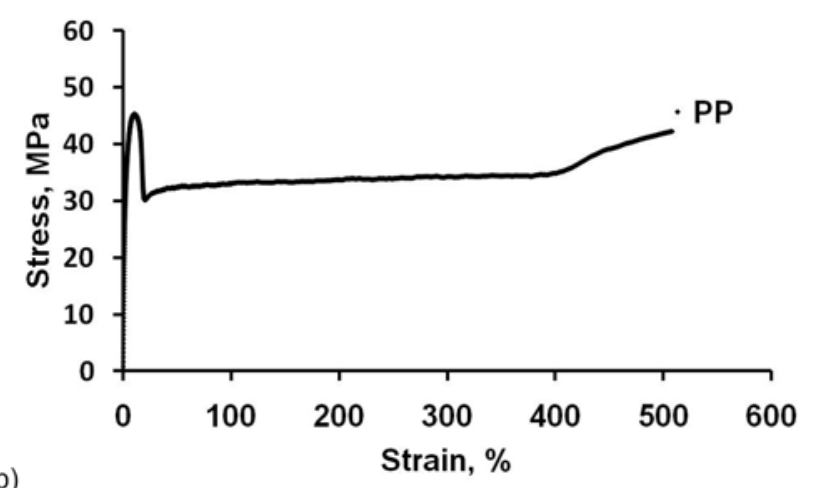

b)

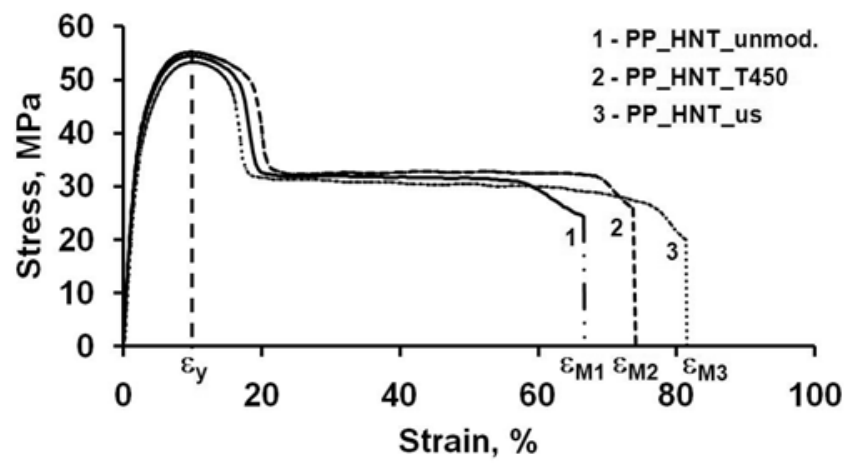

Figure 4. Typical stress - strain curves a) neat PP b) composites of PP with HNT at 3 wt.\%

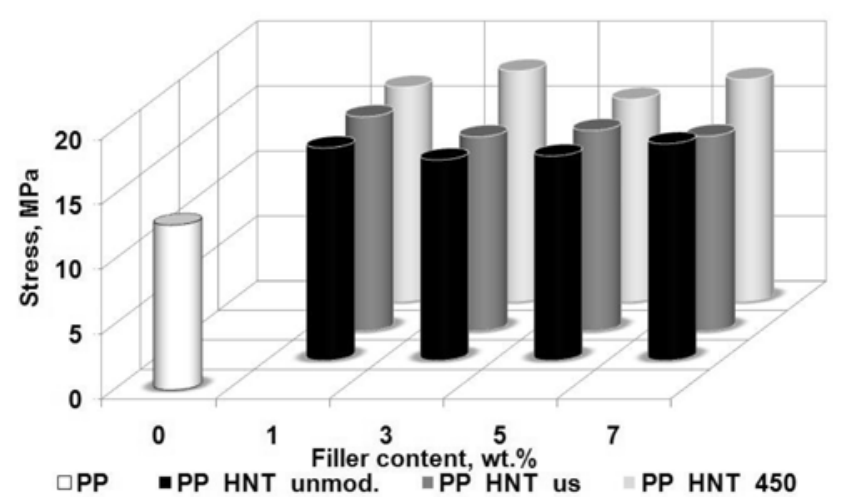

Figure 5. The influence of HNT content and modification type on the stress at break value

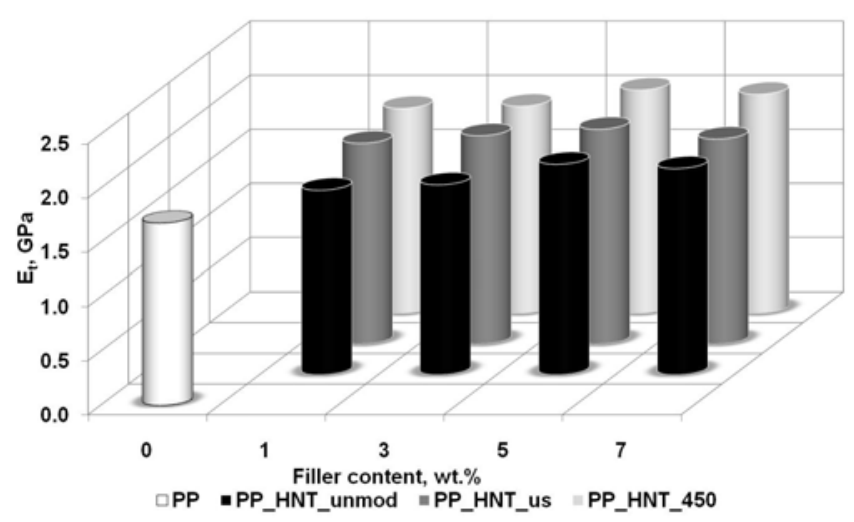

Figure 6. The influence of the content and HNT modification method on the value of Young's modulus of elasticity

The data presented in Fig. 6-7 show that using HNT_450 as a filler has the most significant influence on increasing the value of Young's modulus of elasticity $\left(E_{t}\right)$ and modulus of flexural $\left(\mathrm{E}_{\mathrm{f}}\right)$. The analysis of the data indicates that the increase of the HNT content varied from $0 \mathrm{wt} . \%$ to $5 \mathrm{wt} . \%$

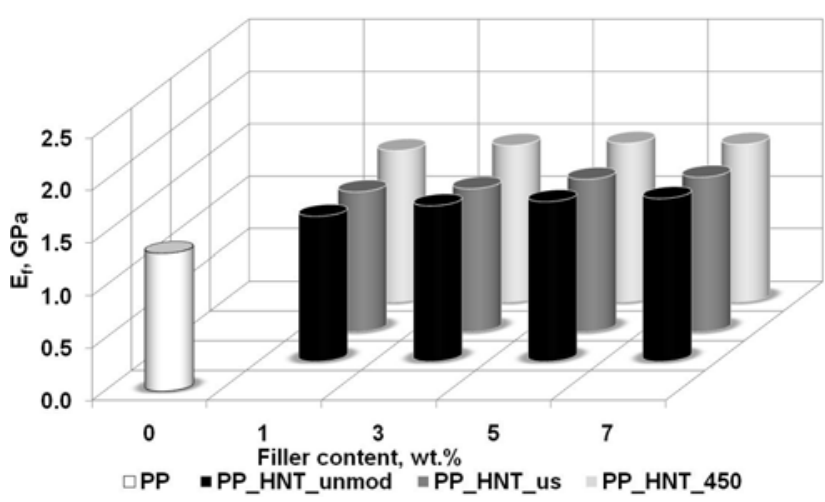

Figure 7. The influence of the content and HNT modification method on the value of Young's modulus of flexural

lead to the increase of the module of elasticity (Young's modulus) independent on type HNT. The highest value of the module was observed at $5 \mathrm{wt} . \%$. HNT. Further increase of the HNT content lead to decrease of modulus of elasticity. The highest value of Young's modulus of flexural was reached in the case of the composite of PP with halloysite thermally modified at $450^{\circ} \mathrm{C}$ and the lowest value was observed for neat PP.

The analysis of the influence of the HNT content on Charpy impact strength of the obtained composites is presented in Fig. 8.

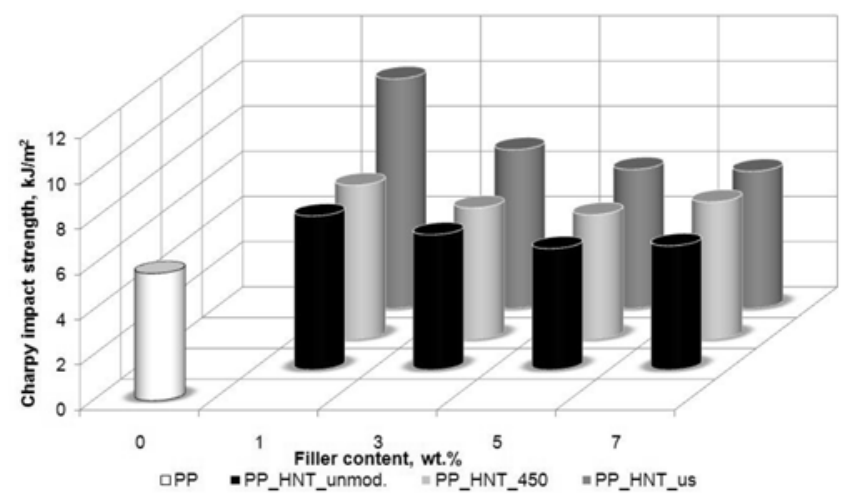

Figure 8. The influence of the HNT content on Charpy's impact strength of composite

The graph shows that the highest Charpy impact strength was achieved for the composites containing respectively 1 and 3 wt. $\%$ of HNT modified by ultrasonic. The improvement of Charpy impact strenght (Fig. 8) was also observed for the composites containing 1 wt. $\%$ of unmodified HNT and halloysite thermally modified at $450^{\circ} \mathrm{C}$ (HNT450). However, the results show that the composite based on halloysite thermally modified at $450^{\circ} \mathrm{C}$ has higher Charpy impact strenght than the composite with unmodified HNT.

\section{Analysis of thermal properties}

The analysis of the influence of the content and HNT modification method on the melting temperature done using Difference Thermal Analysis (DTA) is presented in Table 2 and on the thermograph in Fig. 9. The analysis of the softening temperature of the obtained composites was also performed and its results are presented in Fig. 10.

On the basis of these results it can be concluded that the curves of all the composites (Fig.9) take a similar course. However, the analysis of the data in Table 2 suggests significant differences both in the values of melting enthalpy $\Delta H$ 
Table 2. Analysis of thermal properties of composites using DTA method

\begin{tabular}{|l|c|c|c|c|}
\hline \multirow{2}{*}{ Composite/ Parameter } & $\begin{array}{c}\text { Content } \\
\text { HNT, } \\
{[\mathrm{wt.} \%]}\end{array}$ & Enthalpy of fusion, $\Delta \mathrm{H},[\mathrm{J} / \mathrm{g}]$ & $\begin{array}{c}\text { Crystallinity degree, } \\
\mathrm{S}_{\mathrm{K}}, \%\end{array}$ & $\begin{array}{c}\text { Melting temperature } \\
\mathrm{T}_{\mathrm{m}},{ }^{\circ} \mathrm{C}\end{array}$ \\
\hline PP & 0 & 40.7 & 19.66 & 174.9 \\
\hline \multirow{2}{*}{ PP_HNT_unmod. } & 1 & 49.0 & 23.67 & 178.6 \\
\hline \multirow{2}{*}{ PP_HNT_450 } & 7 & 40.0 & 19.32 & 174.4 \\
\hline \multirow{2}{*}{ PP_HNT_us } & 1 & 52.6 & 25.41 & 181.1 \\
\cline { 2 - 5 } & 7 & 45.4 & 21.93 & 175.6 \\
\cline { 2 - 5 } & 1 & 49.5 & 23.91 & 179.5 \\
\hline
\end{tabular}

and the values of melting temperature $\left(\mathrm{T}_{\mathrm{m}}\right)$. The highest values were recorded for the composites containing $1 \mathrm{wt} . \%$ of HNT. Increasing the content of the filler to $7 \%$ resulted in lowering $\mathrm{T}_{\mathrm{m}}$.

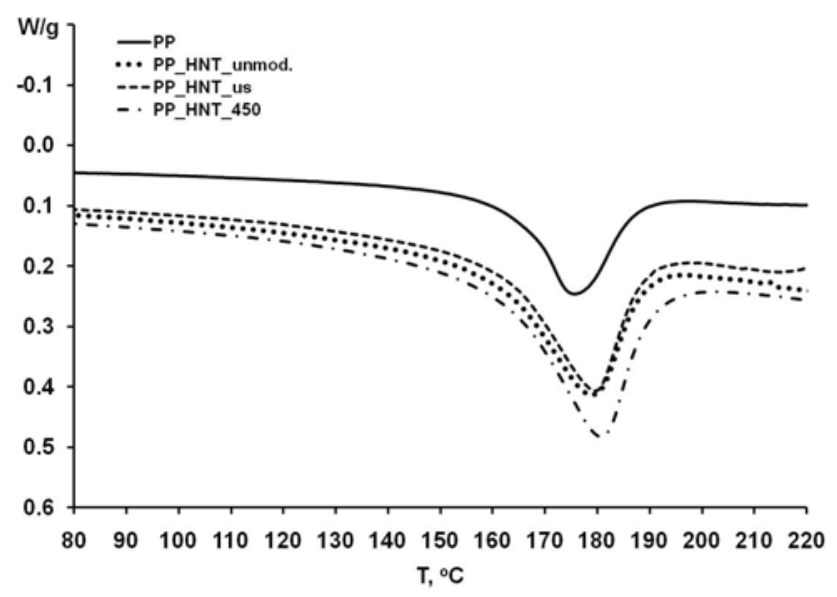

Figure 9. DTA thermograph of composites with $1 \mathrm{wt} . \% \mathrm{HNT}$

A significant rise in melting enthalpy was observed for the composites containing a filler at $1 \%$ of the weight. The highest value $\mathrm{DH}(52,6 \mathrm{~J} / \mathrm{g})$ was observed in the case of the composite containing PP_HNT 450 at $1 \mathrm{wt} . \%$, and the lowest $(31,4 \mathrm{~J} / \mathrm{g})$ for PP_HNT_us at $7 \mathrm{wt} . \%$ The decrease of the value of enthalpy may suggest the creation of the crystal phase in PP under the influence of HNT.

Besides measuring the thermal properties of the composites using DTA method, measurements of dropping point were also made. The results are presented in Fig. 10.

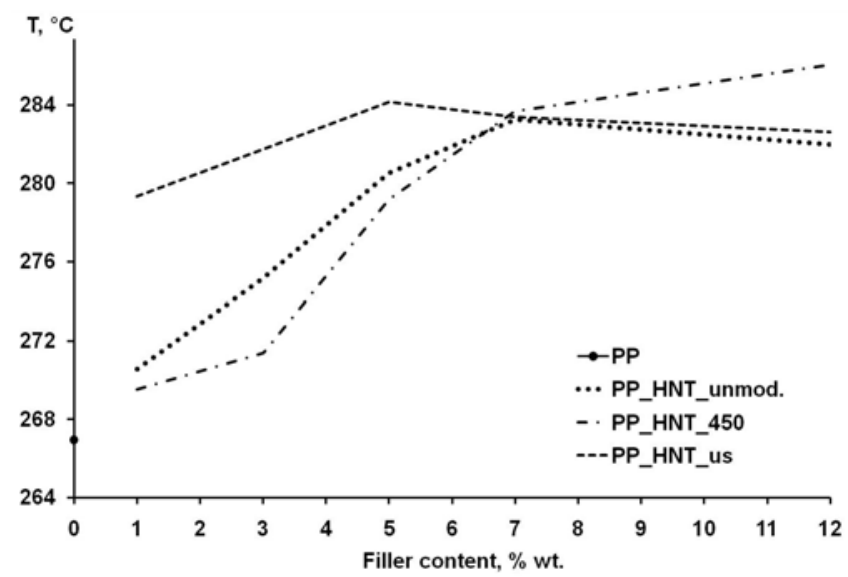

Figure 10. The influence of the content and HNT modification method on composites dropping point

The introduction of HNT into PP resulted in increasing the dropping point regardless of the HNT content and its modification method. The highest increase in dropping point was observed in composites containing HNT at no more than 5 wt. $\%$.

\section{SUMMARY AND CONCLUSIONS}

The results presented in this paper indicate the possibility of acquiring new composites of interesting physical, chemical, mechanical, application and end-use properties, obtained in the process of filling the polypropylene with the modified halloysite (HNT). The properties of the new composites depend on both the content and preparation method of the filler.

\section{LITERATURE CITED}

1. Sarbak, Z. (2005). Clay minerals. LAB Laboratorium, Aparatura, Badania, 3, 9-17 (in Polish).

2. Sarbak, Z. (2005). Natural silicates and aluminosilicates.

LAB Laboratorium, Aparatura, Badania 2, 16-21 (in Polish).

3. Hendricks, S.B. \& Jefferson, M.E. (1938). American Mineralogist, 23(12), 863-875.

4. Veerabadran, N.G., Price, R.R. \& Lvov, Y.M. (2007). Nano: Brief Reports and Reviews, 2 (2), 115-120.

5. Ruiz-Hitzky, E., Ariga, K. \& Lvov, Y. (2007). Bio-Inorganic Hybrid Nanomaterials, Wiley: London, Berlin, 14, pp. 419-441.

6. Lvov, Y.M., Shchukin, D.G., Möhwald, H. \& Price, R.R. (2008). ACS Nano 2 (5), 814-820.

7. http://www.intermark.pl/haloizyt.html

8. Szczygielska, A. \& Kijeński, J. (2010). The application of halloysite as a filler for modification of polypropylene. Part I. The characteristics of halloysite as a filler. Composites, 10(2), 181-185 (in Polish).

9. Ullmans's Encyclopedia of Industrial Chemistry 2002, (6th ed.) (Thermoplastic Materials).

10. Rothon, R.N. (2003), Particulate-filled polymer composites, Rapra Technology Ltd, (2nd ed.)

11. Kurzeja, L., Gibas, E. \& Kubica, S. (2008). Polypropylene with powder carbon filler-shungite. Composites 8 (4), 414-418 (in Polish).

12. Jeziórska, R., (2008). Effect of poly(butylene terephthalate) functionalized with 2,2'-(1,3-phenylene)-bis(2oxazoline) on the structure and properties of polyamide 6 blends with textile waste containing poly(ethylene terephthalate). Polimery, 53 (3), 201-207 (in Polish).

13. Du, M.L., Guo, B.C. \& Jia, D.M. (2006). Thermal stability and flame retardant effects of halloysite nanotubes on poly(propylene), Eur. Polym J., 42, 6, 1362-1369. doi:10.1016/ j.eurpolymj.2005.12.006.

14. NanturalNano Inc., NaturalNano successfully trials halloysite nanotubes in polypropylene, Plastics Additives \& Compounding May/June 2007, 12.

15. Ning, N.-Y. (2007). Crystallization behavior and mechanical properties of polypropylene/halloysite composites, Polymer, 48, 25, 7374-7384. 
16. Liu, M., Guo, B., Lei, Y., Du, M. \& Jia, D. (2009). Benzothiazole sulfide compatibilized polypropylene/halloysite nanotubes composites, Appl. Surf. Sci., 255, 4961-4969. doi:10.1016/j.apsusc.2008.12.044.

17. Liu, M, Jia, Z., Liu, F., Jia, D. \& Guo, B. (2010). Tailoring the wettability of polypropylene surfaces with halloysite nanotubes, J. Colloid Interf. Sci., 350, 186-193. doi:10.1016/j.jcis.2010.06.047.

18. Koszkul, J., Polypropylene and its composites, Monograph Czestochowa Uniwersity of Technology, 1997, 50, pp.87 (in Polish).

19. Collected Applications Thermal Analysis Thermoplastics, Mettler Toledo 2003, pp. 59-60.

20. Sorrentino, L. et al., (2009). Nano/microcomposites based on PP, nanoclay, and $\mathrm{CaCO}_{3}$, J. Appl. Polym. Sci., Wiley Periodicals, Inc., 113(5), 3362, doi: 10.1002/app. 